\title{
A porção carioca do rádio
}

brasileiro

SONIA VIRGÍNIA MOREIRA é professora da Faculdade de Comunicação Social da Universidade do Estado do Rio de Janeiro e presidente da Intercom - Sociedade Brasileira de Estudos Interdisciplinares da Comunicação (2002-05).

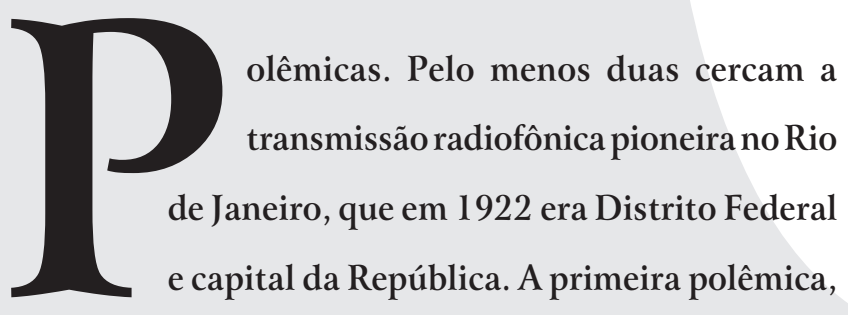
anterior à demonstração inédita durante as festividades do Centenário da Independência, em setembro de 1922, envolveu a ocupação do espaço urbano em que aconteceria a transmissão experimental. Os 
pavilhões da feira internacional comemorativa, por onde foram distribuídos os alto-falantes que irradiaram a novidade sonora, haviam sido construídos entre 1921 e 1922 na esplanada que surgiu com o desmonte do Morro do Castelo, elevação situada no lado carioca da entrada da Baía da Guanabara. "Berço da cidade, referência constante no cotidiano da capital desde os tempos coloniais, o 'velho' Castelo estava associado a uma tradição e a um passado que deveriam necessariamente ser repensados em um contexto de comemoração do Centenário da Independência" (1). Com o morro arrasado pretendia-se preparar a capital do país para o ingresso na modernidade, ao estilo das capitais européias, deixando para trás as características coloniais defendidas por uma parcela da população local e representadas de forma inequívoca nas construções e rotinas de vida das vielas do Castelo.

O rádio aparece no Rio de Janeiro em meio a esse espírito de modernização urbana, como meio de comunicação tradutor por excelência do "novo" que começava a ser mostrado à sociedade naquele início do século XX. Os ecos de admiração país afora provocados pela transmissão experimental sonora no ambiente comemorativo montado na Esplanada do Castelo geraram a segunda polêmica. A capital da República não teria sido a única cidade a sediar emissão radiofônica pioneira: em Recife, abastados, intelectuais e jornalistas - reunidos em um grupo amador de recepção telegráfica - haviam fundado em abril de 1919 o Rádio Clube de Pernambuco, reali-

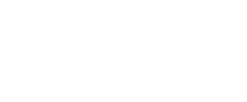


zando também em 1922 alguns testes com transmissores franceses de radiotelegrafia.

Independente das polêmicas, a primeira emissora carioca, Rádio Sociedade do Rio de Janeiro, foi fundada em abril de 1923 pelo médico, antropólogo, cientista e professor Edgard Roquette-Pinto. Para tanto, contou com a participação ativa do presidente da Academia Brasileira de Ciências, o astrônomo e engenheiro industrial Henrique Morize, também nomeado o primeiro presidente da Rádio Sociedade. O fato de ser resultado da iniciativa de cientistas determinou o caráter educativo da emissora, modelo que seria adotado pelas estações pioneiras instaladas na capital e em outros pontos do país no ciclo inicial de dez anos do rádio brasileiro, compreendido entre 1922 e 1932.

Durante as fases de implantação e consolidação da mídia rádio no conjunto da sociedade do Rio de Janeiro, os endereços ocupados tanto pela Rádio Sociedade como pelas emissoras precursoras servem como elementos apropriados para rastrear a inserção das estações no espaço urbano da capital da República. Contribuem ainda para que tenhamos, hoje, uma noção mais aproximada do ambiente formado pelas forças políticas, econômicas, sociais e acadêmicas em meio ao qual se instalou, na época, a nova mídia. Anunciada nos salões da Academia Brasileira de Ciências, a Rádio Sociedade teve seus transmissores instalados em seguida no anfiteatro de Física da Escola Politécnica. Ocupou os salões do torreão da Casa Guinle, nas imediações da Avenida Rio Branco, até passar para o Pavilhão da Tchecoslováquia, construção cedida pelo governo daquele país depois de encerrada a feira internacional do Centenário da Independência.

Do prédio erguido na Esplanada do Castelo, a Rádio Sociedade começou a transmitir sua programação para a cidade. Registro daquele período indica que, "em 7 de setembro de 1923, já de posse da Estação Pekan que lhe fora oferecida pela Casa Pekan, de Buenos Aires, começou a transmitir regularmente. Na sua sede atual, a Companhia Radiotelegraphica Brasileira instalou a estação Marconi, de que se serve a Rádio Sociedade. Essa estação tem potência, no primário, de $6 \mathrm{~kW}$, transmitindo em onda de quatrocentos metros" (2). No trecho urbano planejado para aparecer ao mundo como vitrine da atmosfera existente no Brasil, símbolo de outra etapa na trajetória de desenvolvimento da nação, instala-se em definitivo o novíssimo meio de comunicação eletrônica, o rádio. Na década de 1920, como centro do poder decisório nacional, o Rio de Janeiro, então Distrito Federal, refletia o espírito da época na ocupação do centro da cidade. As transmissões da Rádio Sociedade difundiam o avanço da tecnologia de comunicação a distância, gerando impulsos sonoros disseminados na forma de discursos e peças musicais, e repercutiam os acontecimentos para a sociedade local e nacional.

Na sequiência de implantação das novas emissoras, entre as seis estações fundadas nas décadas de 1920 e 1930, algumas seguiram roteiro de vínculo urbano semelhante ao da rádio pioneira, estabelecendo-se em endereços no centro, enquanto outras estações alojaram-se na zona portuária da cidade. O Rádio Club do Brasil, grupo reunido pelo engenheiro Elba Dias, criou a sua primeira sede em 1924 no Largo da Carioca, "nos altos da Livraria Globo e mandando para o ar a PRA-3" (3). Estava, então, a emissora vinculada a uma livraria. A RádioEducadora do Brasil, ao surgir em 1926, também se instalou no centro do Rio de Janeiro. No mesmo ano, a Rádio Mayrink Veiga passou a funcionar como um departamento da Casa Mayrink Veiga, de importação e exportação, localizada na região portuária da Praça Mauá, na então Rua Municipal no 20. Alguns anos depois a rua teve o nome trocado para o da rádio, desde então abrigada em prédio próprio, onde funcionou até o seu fechamento pelo regime militar em 1965.

A Rádio Cruzeiro do Sul (depois Tamoio) foi a única a se estabelecer fora do eixo centro-zona portuária, funcionando por um breve período, em 1933, em uma casa na Rua Mariz e Barros, no bairro da Tijuca. Em seguida teve o estúdio transferido para 
a Cinelândia, mais precisamente para o 10ํㅜㅇ andar do edifício do cinema Império. $\mathrm{Na}$ Rádio Cruzeiro do Sul começaram os programas de calouros em 1935, comandados por Edmundo Maia e Paulo Roberto e, mais tarde, por Ary Barroso (4). Coração político-cultural do Rio de Janeiro, a Cinelândia reunia os prédios da Biblioteca Nacional, do Museu Nacional de Belas Artes, do Theatro Municipal, do Supremo Tribunal Federal, do Senado Federal, da Câmara do Distrito Federal e dos cinemas Pathé, Odeon e Império. Em ruas próximas funcionavam teatros populares, como o Rival (onde os senadores apreciavam as vedetes dos teatros de revista, algumas delas cantoras no rádio) e o Tabuleiro da Baiana, ponto final dos bondes que ligavam o Centro à Zona Sul, localizado ao lado do prédio do Hotel Avenida. Em 1935, a Rádio Jornal do Brasil incorporou-se ao seleto círculo de emissoras sediadas no centro do Rio, inaugurada na sede do jornal na Avenida Rio Branco. A Rádio Tupi do Rio de Janeiro, pioneira da rede emergente das Emissoras Associadas, vinculadas ao grupo impresso Diários Associados, de Assis Chateaubriand, instalou-se ainda em 1935 na zona portuária do Santo Cristo, mais tarde mudando-se para os arredores da Praça Mauá. Em 1936, a Rádio Transmissora Brasileira, canal pertencente à gravadora de discos RCA Victor, instalava-se no 4ํandar do prédio da empresa, na Rua do Mercado no 22, no centro da cidade. A emissora serviu como "berço" de um elenco artístico que em alguns anos figuraria entre as atrações da Rádio Nacional, reunindo profissionais como Radamés Gnatalli, Nelson Gonçalves, Sílvio Caldas, Almirante e Orlando Silva.

Experiência ímpar na década de 1930por nascer na contramão dos padrões das emissoras comerciais, que passam a predominar a partir de 1932 com o decreto de Getúlio Vargas autorizando a publicidade no rádio - havia entrado no ar em 1934, pelas mãos do já então também radialista Edgard Roquette-Pinto e do educador Anísio Teixeira, a Rádio Escola Municipal do Distrito Federal. Inaugurada no dia 6 de janeiro, os seus estúdios ficaram provisoria- mente instalados em prédio localizado no Largo da Carioca, onde Roquette-Pinto organizava o Instituto Nacional de Cinema Educativo (Ince). A Rádio Escola nascia então vinculada a um projeto cultural de âmbito federal. Freqüentavam o endereço no Largo da Carioca jovens cineastas, como o mineiro Humberto Mauro, e o renomado compositor Heitor Villa-Lobos, musicando filmes educativos idealizados pelo antropólogo Roquette-Pinto.

A emissora que durante toda a década seguinte influenciaria a composição do perfil das rádios comerciais brasileiras nasceu discretamente, em maio de 1933, no berço da zona portuária, Praça Mauá nº 7, com o nome de Sociedade Civil Brasileira Rádio Nacional. Abrigada no imponente prédio do edifício de A Noite - vespertino fundado em 1911 por Irineu Marinho e Joaquim Marques da Silva, que na metade dos anos 30 havia se transformado no diário de maior circulação no Rio de Janeiro, com redação e administração espalhadas em vários andares do maior arranha-céu da América do Sul - a Rádio Nacional que se projetaria originou-se de dois momentos, anos mais tarde, com a incorporação dos transmissores da companhia holandesa Philips e a alteração nos estatutos da sociedade.

Em 1935, a emissora adquiriu os equipamentos recém-importados pela Rádio Philips, em operação desde março de 1930, que havia optado por encerrar suas transmissões e o projeto empresarial de manutenção de emissora própria no país para incentivar a comercialização dos aparelhos receptores produzidos pela mesma fabricante. Em 1936 a Sociedade alterou os estatutos. Os fundadores elevaram o capital, de 100 contos de réis para 1.700 contos de réis, com novas cotas subscritas pelos oito sócios, e autorizaram o presidente da sociedade a adquirir uma estação de radiodifusão de 20 kW (5). Integrante do grupo A Noite, a partir de 1936, a Sociedade Civil Brasileira Rádio Nacional inovou ao instituir o contrato como forma de relacionamento trabalhista com os seus profissionais. Até então, a maioria daqueles que tra-
4 Renato Murce, Bastidores do Rádio - Fragmentos do Rádio de Ontem e de Hoje, Rio de Janeiro, Imago, 1976, p. 102.

5 "Relatório dos trabalhos referentes às empresas A Noite S/A S/A Rio Editora e Sociedade Civil Brasileira Rádio Nacional, vol. 1, 27/06/1945" in Luiz Carlos Saroldi e Sonia Virgínia Moreira, Rádio Nacional-o Brasil em Sintonia, São Paulo/Rio de Janeiro, Martins Fontes/Funarte, 1988, p. 16 
balhavam no rádio recebiam por meio de cachês a cada participação em programas. Entre os nomes reunidos entre 1936 e 1939 pela Rádio Nacional figuram os maestros Radamés Gnatalli e Romeu Ghipsman, os cantores e compositores Lamartine Babo e Paulo Tapajós, os speakers Oduvaldo Cozzi, Celso Guimarães e Aurélio de Andrade, o sonoplasta Edmo do Vale, os cantores Orlando Silva, Marília Batista e Araci de Almeida, os produtores Victor Costa, José Mauro e Almirante.

A estatização da emissora por decreto presidencial de Getúlio Vargas em março de 1940 completou o ciclo de consolidação e apogeu da Rádio Nacional. Autorizada pelo mesmo decreto a operar como estação comercial e canal de radiodifusão estatal, a emissora beneficiou-se da dupla fonte de receita (a publicidade e os subsídios governamentais) entre 1940, data da estatização, e 1945, quando Vargas deixou o poder. Nesses cinco anos, o $21^{\circ}$ e o $22^{\circ}$ andares do edifício na Praça Mauá no 7 constituíram o endereço da emissora-referência nacional, justificando como em nenhum outro momento o seu nome original. O período final dos quinze anos da era Vargas, iniciada na Revolução de 1930, foi carregado de simbolismos noque se refere ao relacionamento mantido entre o Estado e o mais poderoso veículo de comunicação à época. Dos estúdios e auditório na zona portuária, a Rádio Nacional transmitia uma programação elaborada em estreita sintonia com o Palácio do Catete, gabinete e residência do presidente, sede do governo da República.

Entre 1940 e 1942 a emissora produziu e transmitiu para boa parte do Brasil programas de evidente valor cultural. Ritmos musicais, produções dramáticas, informativos sonoros e atrações em auditório foram lançados por maestros, compositores, cantores, atores, autores, apresentadores e produtores que encontraram no rádio espaço profissional de reconhecido prestígio. A partir desse período, e nesse contexto, disseminou-se a política de integração nacional, projetada pelo governo Vargas para propagar o regime ancorado na ideologia do Estado Novo, da qual a Rádio Nacional foi a principal porta-voz. Em $1^{\circ}$ de janeiro de 1943, o alcance da emissora aumentou consideravelmente com a inauguração de uma estação de ondas curtas e a instalação de oito antenas para transmissões ao exterior. À política de integração nacional agregou-se a política de divulgação internacional. A Rádio Nacional começou a transmitir, em quatro idiomas e horários variados, crônicas, notícias e programas cujo conteúdo era o Brasil - sua cultura, suas instituições, sua gente, sua geografia, seus produtos - de acordo com o figurino nacionalista getulista.

Pela localização dos estúdios e do auditório da rádio, a Praça Mauá e as imediações da Avenida Rio Branco celebrizaramse como o reduto dos principais nomes do rádio local e de influência nacional. Não são poucas nos depoimentos gravados e mantidos no acervo do Museu da Imagem e do Som do Rio de Janeiro as referências a esse trecho da cidade, da parte dos personagens que viveram a rotina de produção diária da Rádio Nacional. Paulo Tapajós, Almirante, Renato Murce, Apolo Correia, Floriano Faissal, Marlene e Lourival Marques estão entre as vozes que registraram fragmentos da memória do período ao recordar que muitas peças musicais, capítulos de radioteatro, marchas carnavalescas, piadas de programas humorísticos, bem como textos e músicas de jingles publicitários, foram criados, redigidos ou compostos nas mesas de bares, leiterias, restaurantes e confeitarias que faziam parte da aura boêmia a cercar aquele reduzido mas fervilhante trecho capital da República na primeira metade da década de 1940 . O espaço urbano integrava-se à criatividade dos profissionais que, por sua vez, construíam no ambiente radiofônico a atmosfera que iria permear a relação com a audiência, o imaginário dos ouvintes.

Oitenta anos depois da primeira transmissão de rádio, resistem no centro do Rio de Janeiro parcimoniosos vestígios, que escondem tristes relíquias, da radiofonia carioca. Na Praça Mauá, no prédio hoje ocupado pelo Instituto Nacional de Propriedade Industrial (Inpi), a Rádio Nacional, 
sob controle do Estado, agoniza no 21은 andar, sem investimento em equipamentos, recursos humanos e estratégia de gestão. Na região portuária da Saúde, atrás da Estação de Ferro Central do Brasil, os estúdios da Rádio Tupi ocupam salas no prédio de linhas modernas projetado nos anos 1950 por Oscar Niemeyer para a sede dos Diários Associados. O segmento FM da Rádio Jornal do Brasil mudou-se para o endereço da Avenida Presidente Vargas 435, 20 andar. Na Avenida Rio Branco, sede do antigo Jornal do Brasil, desde 2001 e sob novo controle acionário instalou-se o jornal no $13^{\circ}$ andar da construção moderna em aço e vidro que se ergueu no lugar do edifício original.

Das imagens, talvez a mais reveladora da degradação na forma de inserção das emissoras no espaço urbano carioca seja a da Mayrink Veiga, a rádio "coqueluche" da década de 1930, que em 1985 mereceu a descrição a seguir.

“O prédio da Rua Mayrink Veiga permanece de pé. Mas quem passa por ele, hoje, jamais suporá que ali funcionou uma rádio 'com uma história riquíssima', como afirmou Lourival Marques. No prédio agora funciona uma garagem totalmente depredada, sem portas, janelas sem vidros, sem pintura, lâmpadas ou qualquer tipo de cuidado. Em seu interior, apenas carros e insetos. Na entrada, quase na calçada, um guardador uniformizado. Os andares de cima não são utilizados. Contam que a programação da PRA-9 no dia do fechamento permaneceu afixada na porta do prédio por muito tempo" (6).

Apesar da trajetória reconhecidamente comercial, a rádio esteve envolvida em um jogo de interesses político-ideológicos na década de 1960, com maior intensidade no período anterior ao golpe militar de 1964. O seu fechamento, ao ter cassada a concessão, simbolizou a escalada das restrições à liberdade de expressão impostas ao conjunto da mídia brasileira nas décadas de 1960 e 1970. Depois dos anos 60, o rádio carioca nunca mais foi o mesmo.

\section{VOZES DA RÁDIO NACIONAL}

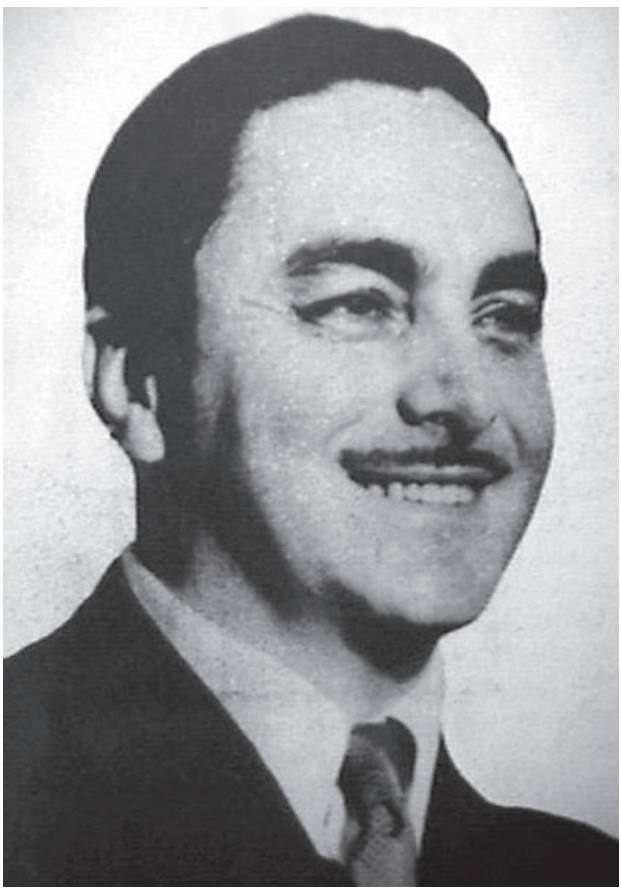

Celso Guimarães (ao lado)

representou, durante décadas, o padrão de excelência mantido pelos locutores da grande emissora brasileira. Por outro lado, Nélio Pinheiro (abaixo) vivia personagens românticos em novelas que faziam sucesso em todo o Brasil

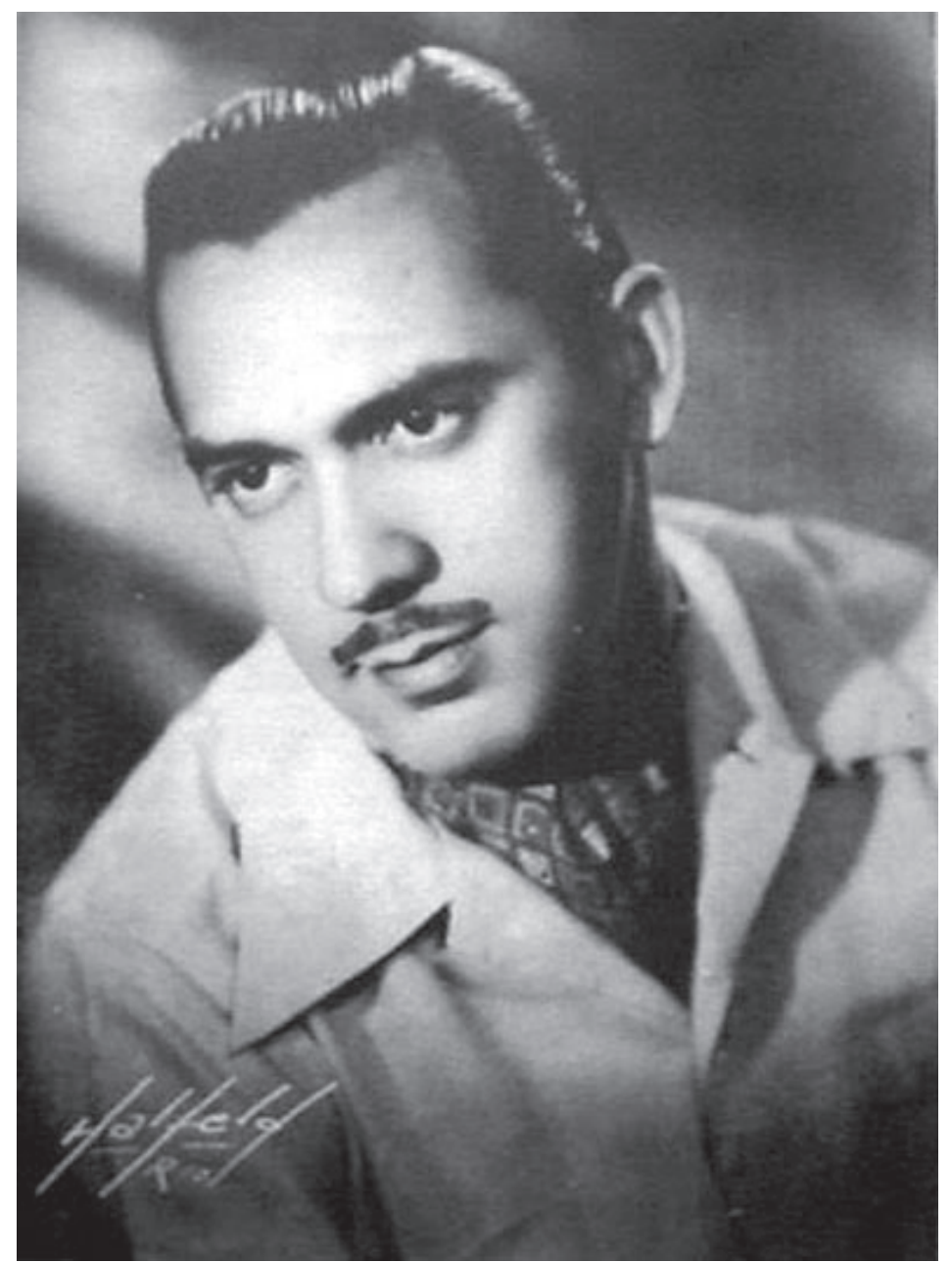

